\title{
Behavioral therapy for urinary incontinence in elderly women: an experience of trans personal care
}

\begin{abstract}
Urinary in continenceis a problem that affects both men and women, being more prevalent in elderly women. Behavioral therapy is an approach developed by nurses to control incontinence and involves several dimensions of the human being, including sexual. The objective is to report the experience of implementing behavioral therapy for urinary incontinence based on Jean Watson's Theory of Transpersonal Care. Six women participated in the study monitored from July to November 2020. All patients reported improvement in in continence symptoms, five of whom had no involuntary loss of urine. It is not necessary to refer them for surgical treatment or drug therapy. There was an improvement in the elderly woman's self-esteem and engagement for self-care. The study revealed that it is possible to control the urinary incontinence of elderly women and consequently, contribute to the quality of life reduce the cost and value the relationship of the elderly woman with yours exuality.
\end{abstract}

Keywords: aged, women, urinary incontinence

\author{
Volume 6 Issue | - 202 | \\ Barbara Martins Corrêa da Silva,' Claudia \\ Feio da Maia Lima, ${ }^{2}$ Célia Pereira Caldas ${ }^{3}$ \\ 'Clementino Fraga Filho University Hospital - HUCFF, Rio \\ de Janeiro (RJ), PhD student in Nursing, Rio de Janeiro \\ StateUniversity (RJ), Brazil \\ ${ }^{2}$ Assistant Professor at the Nursing School from the Federal \\ University of Recôncavo da Bahia, Santo Antônio de Jesus (BA), \\ Doctor in Nursing, Rio de Janeiro State University (RJ), Brazil \\ ${ }^{3} \mathrm{PhD}$, Associate Professor at the School of Nursing, Rio de \\ Janeiro State University (RJ),Vice-Director of the un ATI - UERJ, \\ Brazil
}

Correspondence: Barbara Martins Corrêa da Silva, Clement ino Fraga Filho University Hospital - HUCFF, Rio de Janeiro (RJ), $\mathrm{PhD}$ student in Nursing, Rio de Janeiro State University (RJ), Brazil, Email barbaramartins.enf@gmail.com

Received: January 10, 202I | Published: January 24, 2021

\section{Introduction}

Urinary incontinence(UI) is characterized by involuntary loss of urine and can be classified according to the complaint in effort UI, when involuntary loss of urine occurs when making an effort such as coughing and sneezing; Urgent UI, when a strong urination desire occurs; Mixed urinary UI when involuntary loss occurs in these two conditions. ${ }^{1}$ UI can reach men and women, but in the study the female population is the object of research. It is estimated that between 15 and $55 \%$ of them complain of inferior urinary symptoms. ${ }^{2}$ Behavioral therapy (CT) for UI consists of guidance on life style habits, promotion of self-care, voiding diary, perineal exercises and assessment of the patient's response to therapy. ${ }^{3}$

Through out these years, behavioral therapy was applied in the geriatric out patient clinic, withthe nurse being aware of the sexual dimension, as it addresses the various dimensions of the human being. In this therapeutic process, the elderly women reported the sexual history of reproductive, affective life and the relationship with their body, thisis because when performing an amnesis and physical examination, the nurse and the elderly woman retrieved data related to the pelvis. In the office, the elderly women verbalized stories about the development of sexual characters, the process of discovering the body, pleasure, married life, child birth, rape, all stories with positive or negative cumulative effects with their sexuality.

There are very rich aspects to be explored in this care relationship, and the motivation for further studies on this theme. Still onthe direct relationship between urinary and sexual dysfunction, it is known that the lossof urine during intercourse, night time losses, fear of episodes of loss in public and, therefore, bad smell is associated with altered image and self-esteem. ${ }^{4}$ It is also noted that the negative impact on sexuality occur seven in the absence of a partner, as is the case of elderly widows, divorcedor single. ${ }^{5}$ Currently, the International Consensus on
Sexual Medicine, International Classification of Diseases (ICD-10) and the Diagnostic and Statistical Manual of Mental Diseases (DSM5) adopt a non-linear model of female sexual response, integrating emotional, psychological, cognitive and external sexual stimulants. Thus, sexual desire is different from sexual arousal, which in turn differs from sexual satisfaction, but these elements are related to each other and their combination is essential for sexual health. ${ }^{6}$

There is a stereo type that the elderly no long erexperience their sexuality, as if aging carries with them a lack of interest in life. However, there are otherways for the elderly to experience their sexuality, such as a long hug; a loving kiss; intimacy; sensuality; touch and discover that there is still pleasure to be explored. ${ }^{7}$ The elderly person's sexuality expressions are closely linked to previous experiences and to the perception of biopsychosocial changes. ${ }^{8}$ Thus, despite the expected outcome of behavioral therapy being defined objectively, the subjectivities that affect this process all owan exchange between those who care and those who are cared for, making this relationship as therapeutic as the $\mathrm{CT}$ intervention. In this perspective, this study has as objectthe CT for UI of the elderly as an experience of transpersonal care in approaching their sexuality. Under standing sexuality as the subject's intimacy, looking at one self promotes a reunion with its essence and history, directing the adequacy of the applicationo f Jean Wats on's Theory of Nursing of Human Care for this study, because knowledge of one selfis a way of expansion of restructuring capacities. ${ }^{9}$

Transpersonal careis a transformation in which the individual moves towards a high sense of being and in harmony with his mind, body and spirit. Transpersonal care frees feelings, allows the client, there cipient of care, to better as similate the condition of his own being. Such as similation can lead to there organization of the perceived and experienced self. ${ }^{10}$ 
The aim of the article is to report the experience of implementing behavioral therapy for urinary incontinence based on Jean Watson's Theory of Transpersonal Care.

\section{Methodology}

This is an experience report on the implementation of behavior altherapy applied to elderly women with urinary incontinence based on Jean Watson's Theory of Human Care (Figure 1).

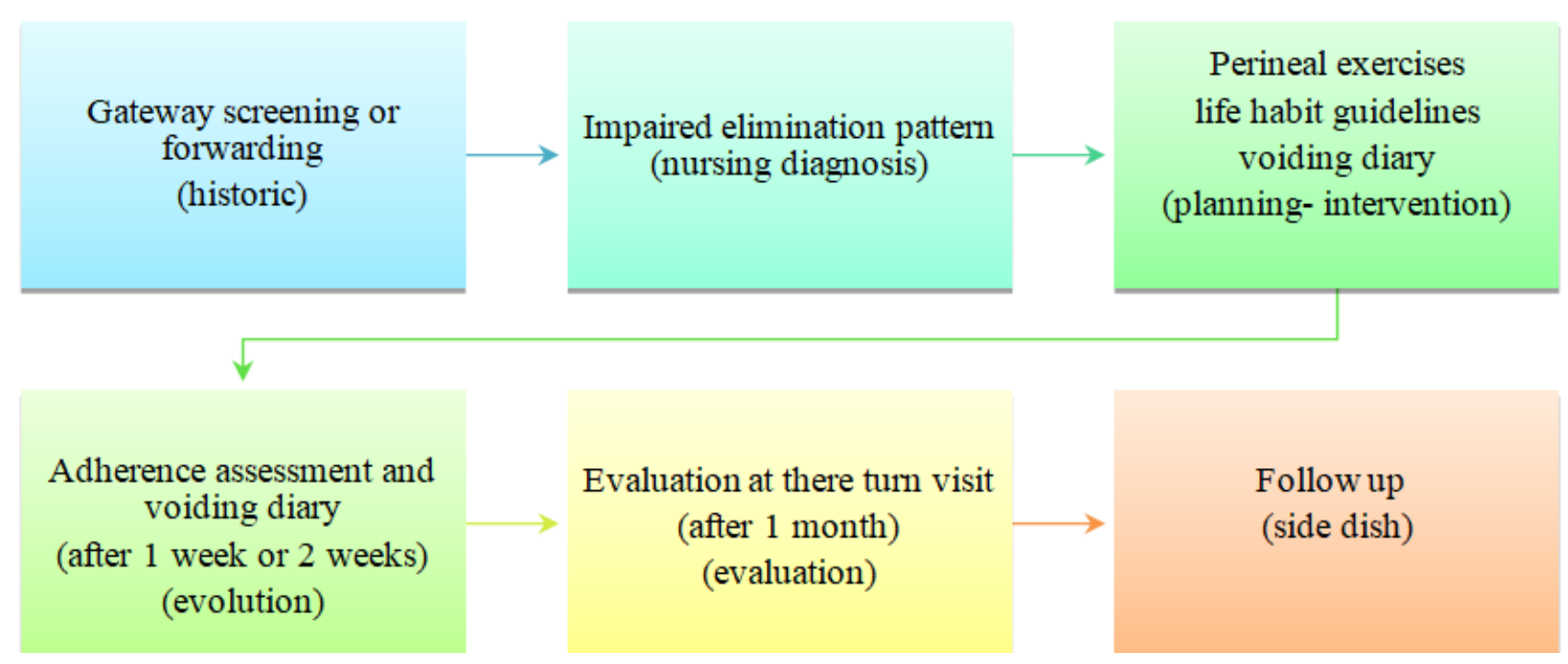

Figure I Stages of the systematization of nursing care for elderly woman's behavioral therapy in the geriatric out patient clinic. Rio de | Janeiro, RJ, 2020.

The inclusion criteria are women over 60 years of age who have a clinical complaint of involuntary loss of urine linked to the geriatric out patient clinic of the study hospital and who voluntarily accept the invitation to participate in the study by signing the Informed Consent Form. The exclusion criteria are elderly women who have cognitive in capacity to understand the guidelines performed in behavioral therapy, as it will not be possible to perform the perineal exercises or perform the voiding diary and behavioral changes. This cognitive disability will be seen in the first approach to behavioral therapy during the nursing consultation. Illiterate elderly women will also be excluded from the study, as they will have difficulties in making the voiding diary.

The place of study was the Geriatric Clinic of the University Hospital Clement ino Fraga Filho, Rio de Janeiro - RJ, and has a structure that occupies 110 thous and square meters. Its visionis to be a center of excellence in assistance, teaching and research, and its mission is to develop teaching and research actions in line with the university's social function, linked to assistance, highly complex health and integrated into the Unified System. of Health (SUS), promoting quality care to its public and in accordance with ethical and humanistic principles.

The out patient clinic is the main entrance to the Clement ino Fraga Filho University Hospital. It is subordinate to the Community Health Division and operates on the 1st floor of the hospital, from Monday to Friday, from 7 amto $5 \mathrm{pm}$.

The geriatric out patient clinic is aimed at patients over the age of 60 , with a score above 8 on the vulnerability assessment (IVCF20), including patients with geriatric syndromes (iatrogenesis, family failure, cognitive disability, incontinence urinary and fecal conditions, immobility, postural instability, sensory disability, visual and auditory deficits), which require specialized monitoring in gerontology by a multi professional teamand their caregivers, using health education, promotion, maintenance and restoration strategies and disease prevention aiming to provide greater independence and autonomy, determinants of good health and quality of life for this population.

The gate way to care for these elderly people is through a SISREG regulation system (referral from the family clinic), or opinion (patients who already have medical records in the hospital, but are referred by ot her clinics).

\section{Data collect}

Six women participated in the study from July to November 2020. Data collection was compromised due to the coronavirus pandemic. Since the clinic was closed during this entire period for 6 months. In effect, we reduced the number of services to avoid contamination.

Nursing collection was performed during the nursing consultation. For each participant, four nursing consultations were carried out with an average duration of 30 minutes.

\section{The data were analyzed from the perspective of Jean Watson'sTheory}

The assessment of the effectiveness of behavioral therapy will be analyzed based on the patient's response to the data collection script. Since 1997, it is recommended that quality of life measures be included in all clinical researchon UI, as an additional complement to traditional clinical parameters. ${ }^{11}$ For this reason, the ICIQ-SFInternational Consultationon Incontinence Questionnaire will be used - Short Form with cross-cultural validation for Portuguese.

\section{Ethical aspects}

Prior to data collection, the study was authorized by the Research Ethics Committee in Brazil with the following registration number CAAE 27172419.0.0000.5257. This is a research of strategic interest for SUS, as it proposes to reduce technological dependencies for care.

The identification of research participants will be kept anonymous during all phases of the study, in accordance with the guidelines 
and standards for research involving human beings established by Resolution No. 466 of the National Health Council of December 12, 2012;12 the specific Resolution of social research Resolution 510 ofApril 7, 2016 ${ }^{13}$ and Resolution 580 of March 22, 2018 that better describes item 4 of resolution 466 with respect to research terminologies, especially those carried out in SUS. This research meets the ethical requirement proposed in that resolution, since the results and / or findings of the research will be communicated to the competent authorities, ensuring that research participants are not stigmatized..$^{14}$

The Human and Social Sciences have specificities in their conceptions and in their research practices, in so far as they have a pluralistic meaning of science, which results in the adoption of multiple theoretical and methodological perspectives, and in so far as they deal with attribution so fmeaning, practices and representations, without direct intervention in the human body, with specific nature and degree of risk. Further more, it considers that the researcherparticipant relationshipis continuously built in the research process, and can bere defined at any time in the dialogue between subjectivities, since it implies reflexivity and the construction of non-hierarchical relationships. ${ }^{13}$

There was a Free and Informed Consent Term through which the participating researchers requested the person's authorization for their inclusion in the research. The data collection in strument used as a script covered the 10 steps of the Clinical Caritas Process.

\section{Results}

All patients reported improvement in in continence symptoms, five of whom had no involuntary loss of urine. It is not necessary to refer them for surgical treatment or drug therapy.

In clinical practice, upon obtaining remission of UI symptoms, the elderly woman improves her self-esteem and starts to expand the list of daily activities. In addition, it reiterates its connection not only with the physical body, but with its essence, as $\mathrm{CT}$ uses breathing exercises associated with pelvic muscle contractions and body self-perception.

It is also noticed that the involuntary loss of urine type of urgency is associated with anxiety, abuse of coffee and other stimulants. The more incontinent, the greater the risk of anxiety, leading to the consumption of stimulants. Table 1 shows the model for monitoring the study participants who under went behavioral therapy for urinary incontinence at the geriatric out patient clinic. Result of the experience of implementing behavioral therapy based on Jean Watson's Theory of Human Care.

The ten charitable factors considered care need sspecific to human experiences and which were addressed in the studywere:

1. humanistic and altruistic values system;

2. faith and hope;

3. sensitivity to one self and to others;

4. development of relationships of help, trust, care;

5. expression of positive and negative feelings and emotions;

6. creative and individualized problem solving process;

7. transpersonal teaching-learning;

8. supportive, protective and / or corrective, mental, physical, social and spiritual environment;

\section{9. assistance to human needs;}

10. existential-phenomenological and spiritual forces

\section{Discussion}

Urinary in continence has an impact on people's health, as it affects quality of life and is related too ther co-morbidities. For this reason, this problem requires an intervention by the nurse.

Statistically, urinary incontinence is self-reported in $20 \%$ of women and in $6.9 \%$ in men 3 . It is also known that urinary in continence affects $30 \%$ of the elderly living in their homes, 40 to $70 \%$ of hospitalized elderly and 50\% institutionalized elderly. ${ }^{1}$

Bladder eliminations result from a synchronized mechanism of contraction and relaxation of the bladder and intestine sphincters1. Thus, in order to approach patients with urinary incontinence, it isnecessary to know that the urination process is coordinated by the sympathetic and parasympathetic nervous system. The sympathetic nervous system is responsible for the contraction of the sphincter and the para sympathetic system for its relaxation.

Behavioral therapy is the first-line treatment, thatis, it must be started before medication and surgical procedures, which should bereserved for cases refractory to CT. ${ }^{1-3}$

In cases of therapeutic failure or impossibility of treatment, guidance should be given to the patient and caregiver. This can happen in people with advanced dementia, as they are unable to have continence due to neurological reasons. In these cases, the patient will use the geriatric diaper. However, attention should be paid to frequent changeand the maintenance of a diaper change to avoid moisture in the perianal region.

Caringis a shared experience..$^{15}$ Jean Watson's theory is based on humanistic aspects and on the spiritual and ethical dimensions of care, which can ontribute to the development of holistic critical thinking and the role of nurses in the field of care, teaching and research. ${ }^{16}$

Watson proposes in the Caritas Process, the expression of the person as a process of recovery of one'sown health, which can be through art, spirituality and etc ... ${ }^{17}$

The expression Caritas is of Latin origin and means to treat with affection, love, nourish, give special attention, appreciate and be sensitive. ${ }^{17}$

According to Watson, sexuality is a human need that involves personality development, including sexual identification, self-care, self-esteemand reported patterns of human behavior. It cannot be limited to sexual inter course, as it involves satisfaction with a body, withone sex and with good attitudes towards one'sown sex and sexual performance. $^{18}$

\section{Conclusion}

This is an innovative study because it is the only one with a simultaneous approach to Jean Watson'sTheory, urinary incontinence in elderly women and sexuality. Thus, it is inferred that the present study has a contribution to gerontological nursing practices.

This work demonstrated the practicality of the Clinical Caritas Process, as its inherent steps in the care process. The difference is that transpersonal care when doneintentionally opens doors to other possibilities such as: research. 
To address the sexuality of the elderly, it is necessary to take into account that sexual behavioris marked by culture, religion and education. In this sense, the nursing theory of transpersonal care is adequate to study sexuality. Since the focus of the work is not on rescuing sexual practice or merely, on unveiling the sexual history of elderly women, but rather, working with the energy that leads us to seek love, contact, tender nessandintimacy.

As a result, the elderly woman's self-esteem and commitment to self-care improved. Thus, the study revealed that it is possible to controlthe UI of elderly womenand, consequently, contribute to the quality of life, decrease the cost and value the relationship of the elderly woman with her sexuality. The article reiterates the applicability of the Human CareTheory in Nursing care and behavioral therapy for urinary incontinence.

\section{Acknowledgments}

None.

\section{Conflicts of interest}

Author declare that there is no conflict of interst.

\section{References}

1. Lima Cfm Et. Al. Behavioral therapy for the urinary incontinence of elderly woman. J Nursufpeon Line Recife. 2015;9(8):8762-8770.

2. Mota RL. Female urinary incontinence and sexuality. Int Braz J Urol. 2017;43(1):20-28.

3. Caldas CP, Conceição IRS, José RMC, et al. Terapia comportamental para incontinência urinária da mulher idosa: uma ação do enfermeiro. Texto Contexto - Enferm. 2010;19(4):783-788.

4. Karbage Sa. Qualidade de vida de mulheres brasileiras com incontinência urinária e o impacto na sua função sexual. Eur J Obstetg ynecol reprod Biol. 2016;201:56-60.

5. Visser E, De Bock Gh, Berger My, et al. Impacto da incontinência urinária no funcionamento sexual em mulheres idosas da comunidade. J Sex Med. 2014;11:1757-1165.
6. Latif EZ, Diamond MP. Chegando ao diagnóstico de disfunção sexual feminina. Fertilsteril. 2013;100:898-904.

7. Moraes KM, Vasconcelos DP, Silva ASR, et al. Companheirismo e sexualidade de casais na melhor idade: cuidando do casal idoso. Rev Bras Geriatr. Gerontol. 2019;14(4):787-798.

8. Lima CFM, Trotte LC, Souza TA, et al. A sexualidade do cônjuge que cuida do idoso demenciado: revisão integrativa da literatura. Rev Min Enferm. 2015;19(2):211-217.

9. Watson J. Humancarecare: uma teoria da enfermagem. 2nd ed. Ontário: Jones E Bartlett Learning; 2012.

10. Watson J. Enfermagem: ciência humana e cuidar uma teoria de enfermagem. Trad. De João Enes. Loures: Lusociência; 2002.

11. Blaivas Jg, Appel Ra, Fanti Fa. Standards of efficacy for evaluation of treatment outcomes in urinary incontinence: recommendations of the urodynamic society. Neuronalurodynamics. 1997;16:145-147.

12. Brasil. Conselho nacional de saúde. normas para pesquisa envolvendo seres humanos. Resolução No 466. Brasília, Df, 2012.

13. Brasil. Conselho nacional de saúde. Normas para pesquisa envolvendo seres humanos. Resolução Nº 510. Brasília, Df, 2016.

14. Brasil. Conselho nacional de saúde. normas para pesquisa envolvendo seres humanos. Resolução Nº 580. Brasília, Df, 2018.

15. Carvalho, Zmf. Cuidado de enfermagem com a pessoa paraplégica hospitalizada: estudo à luz da teoria de jean watson $(\mathrm{O})$. Fortaleza; S.N Dez. 2002.208P.

16. Mendonça $\mathrm{AB}$. Counseling and spiritual assistance to chemotherapy patients: a reflection in the light of jean watson's theory. Esc Anna Nery. 2018;22(4): E20180081.

17. Riegel F, CMG Oliveria, Siliveria SD. Crossetti maria da graça oliveira, siqueira diego silveira. contribuições da teoria de jean watson ao pensamento crítico holístico do enfermeiro. Rev Bras Enferm. 2018;71(4):2072-2076

18. Araújo EC, Cofer MS, Nóbrega MML. Teoria de enfermagem de jean watsosn articulada com a sexualidade humana. On Line Brazilian Journal Of Nursing. 2005;4(2). 